\title{
Normalized Serum EGF Levels as a Potential Biomarker in Non-Small Cell Lung Cancer: The Role of Platelets
}

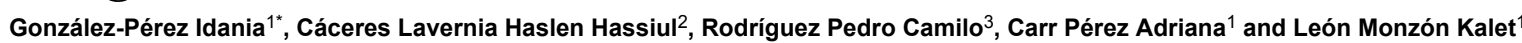 \\ ${ }^{1}$ Department of Systems Biology, Center of Molecular Immunology, 216 Street and 15th Avenue, Atabey, Siboney, Playa, Havana City, Cuba \\ ${ }^{2}$ Department of Oncology, Hermanos Ameijeiras Hospital, San Lázaro Street, Havana City, Cuba \\ ${ }^{3}$ Department of Clinical Trials, Center of Molecular Immunology, 216 Street and 15th Avenue, Atabey, Siboney, Playa, Havana City, Cuba
}

"Corresponding author: González-Pérez Idania, Department of Systems Biology, Center of Molecular Immunology, 216 Street and 15 th Avenue, Atabey, Siboney, Playa, P.O. Box 16040, Zip Code-11600, Havana City, Cuba, Tel: 2022964810; E-mail: idania.gp@gmail.com

Rec Date: September 05, 2018 Acc Date: October 12, 2018, Pub Date: October 19, 2018

Citation: Idania GP, Hassiul CLH, Camilo RP, Adriana CP, Kalet LM (2018) Normalized Serum EGF Levels as a Potential Biomarker in Non-Small Cell Lung Cancer: The Role of Platelets. J Mol Biomark Diagn 9: 402.

\begin{abstract}
Background: Literature reports contradictory findings regarding the capacity of serum EGF concentrations ([EGF]) to differentiate non-small cell lung cancer (NSCLC) patients from healthy individuals. Therefore, the diagnostic capacity of [EGF], suggestive of dependency on this growth factor in NSCLC patients (tumors) and hence indicative of possible response to therapies directed to EGF/EGFR, is still an open question. Inconsistencies likely derive from the lack of harmonization and standardization in methodologies for blood and sera processing.
\end{abstract}

Methods: A cohort of NSCLC patients was evaluated at diagnosis (25) and after first-line-therapy (18/25). Sera were collected $1 \mathrm{~h}$ and $4 \mathrm{~h}$ after phlebotomy, controlling the variables influencing [EGF]. EGF was quantified by ELISA. Platelets count was also estimated. The values obtained for several combined and/or normalized by platelets count, variables, were compared to those in selected cohorts of healthy controls.

Results: We found differences between healthy individuals and NSCLC patients in the accessibility of EGF to circulation, but not in the total available EGF stock. Indeed, we observed a higher fraction of free EGF in the circulation of patients and consequently a lower amount of EGF stored in platelets. Interestingly, an aberrant relationship between EGF and platelets counts was also observed, especially in patients with thrombocytosis. Moreover, several EGF-related variables, with enough accuracy for discrimination, were identified. Particularly, those variables normalized by platelets count made more evident the differences between patients and healthy controls. Therefore, they might be potential biomarkers in NSCLC.

Conclusion: Our results suggest the increase in free/accessible EGF in blood circulation as relevant to the biology of NSCLC, most likely because it reflects a higher accessibility of this growth factor for the tumor. They also suggest some of the study variables to be further evaluated on its predictive value, to select good responders to CIMAvax-EGF ${ }^{\circledR}$ or other therapies targeting the EGF/EGFR system.

Keywords: Non-small cell lung cancer; Epidermal growth factor; Epidermal growth factor receptor; Platelets; Stratification; Diagnostic biomarker; Predictive biomarker

Abbreviations: NSCLC: Non-Small Cell Lung Cancer; EGF: Epidermal Growth Factor; EGFR: Epidermal Growth Factor Receptor; SNP: Single Nucleotide Polymorphism

\section{Introduction}

Lung cancer (LC) is the leading cause of cancer deaths worldwide [1]. Unlike most cancers, which have witnessed steady increases in survival rates, advances have been slow in LC, for which the 5-year survival rate is about $18 \%$ [2]. In Cuba, malignant tumors of trachea, bronchia and lung are a health concern as well, with about 4000 newly cases every year and 5720 deaths in 2017 [3]. However, for non-small cell lung cancer (NSCLC), the most frequent LC type, new immunotherapies have shown a great potential for patients in advanced stages [4]. Moreover, personalized medicine is providing hope by treating patients with drugs that are effective based on specific characteristics of their tumors [5]. The Epidermal Growth Factor
(EGF), known to stimulate the growth of several types of epithelial tissue, possesses strong mitogenic activity on tumor cells that converts this ligand in an attractive target for designing antitumor strategies [6].

CIMAvax-EGF $^{\circ}$ [7] is a proven effective Cuban therapeutic vaccine for advanced NSCLC, which induces anti-EGF antibodies that recognize the EGF in circulation, preventing its binding to EGFR, and then disrupting the associated signal transduction cascade in cancer patients and ultimately cell proliferation. Studies of serum EGF concentrations ([EGF]) in Cuban patients treated with this vaccine revealed that high [EGF] are a factor of bad prognosis for NSCLC and at the same time a predictive biomarker of CIMAvax-EGF ${ }^{\circ}$ efficacy [8-10]. However, the capacity of those concentrations to discriminate between NSCLC patients and healthy individuals (its diagnostic value), suggestive of dependency on EGF in NSCLC patients (tumors) and hence indicative of possible response to therapies directed to this growth factor or its receptor, is still an open question. There are only a few reports available on this topic, some of which have published discrepant findings [11,12]. This inconsistency of results has been presumably caused by the lack of harmonization and sometimes of 
standardization in the methodologies used for blood processing and sera collection. Essentially, the majority of reports do not consider the known dependency between [EGF] and the time of sera separation $[13,14]$. Neither the type of tubes employed for blood collection, which affects clotting times and thus the release of EGF by platelets [15-17], not even the temperature at which blood coagulates, which also impacts this process. Differences in the selection of controls and patients (the lack of control of confounding factors) have also contributed to discrepant results [12].

In this work, [EGF] and platelets counts were quantified in 25 NSCLC patients, using previously standardized methodologies for blood processing and sera separation [14]. Platelet's contribution to [EGF] was studied in patients, showing a clear difference to what is reported for healthy individuals. Several combined and plateletsnormalized EGF-related variables were proposed and evaluated on its capacity to discriminate between patients and healthy individuals. We identified variables with a clear diagnostic value and a simple biological interpretation. Moreover, we used them in an attempt to infer the EGF-dependency in tumors of individual patients. We suggest to further evaluate some of these variables, on its predictive value to select good responders to treatment with CIMAvax-EGF vaccine or other therapies targeting the EGF/EGFR system.

\section{Materials and Methods}

\section{Study design}

The [EGF] were assessed in NSCLC patients at the time of diagnosis (To) and 4-6 weeks after the first-line-therapy (T1).

\section{Phlebotomy and sera separation}

These procedures were performed according to González-Pérez et al. [14]. Each phlebotomy provided two sera, separated at $1 \mathrm{~h}$ and $4 \mathrm{~h}$ after venipuncture, and therefore two $[\mathrm{EGF}]:[\mathrm{EGF}]_{1 \mathrm{~h}}$ and $[\mathrm{EGF}]_{4 \mathrm{~h}}$, respectively.

\section{Patient and control cohorts: Ethical aspects}

Naive patients, with a cytohistological confirmation of NSCLC, a performance status ECOG $<3$, and a measurable disease according to RECIST version 1.1 [18], were recruited from October 2014-May 2016, at Hermanos Ameijeiras Hospital (HAH) in Havana. Those with brain metastasis and chronic diseases other than hypertension and heart disease were not enrolled in the study. Staging was determined according to the $7^{\text {th }}$ edition of the TNM system [19]. A group of 25 patients was evaluated at diagnosis (NSCLC1) and a subgroup of 18 was additionally evaluated after treatment (NSCLC2) (Table 1 and Supplementary Table S1). Therapy consisted on 3-6 cycles of Cisplatin or Carboplatin, administered with Etoposide, Vinblastine or Paclitaxel, every 21 days, in combination or not with radiotherapy (23-60 Gy in 20 fractions over 4 weeks, Table 1). Two healthy control cohorts, balanced by age and gender to match the NSCLC groups (HC1 and HC2 in Supplementary Table S1 and S2), were randomly picked out from a panel of healthy Cuban donors [14]. The members of the third control group $\mathrm{HC} 3$ were selected from the same panel, based on the availability of their platelets count.

The study was approved by the Ethical Committee of HAH. The sera and patient's data were collected in compliance with Helsinki Declaration.

\section{Primary variables}

Platelets count and serum EGF concentrations were considered primary variables. Based on a previous study [14], the EGF measured at the first hour of coagulation $[E G F]_{1 h}$, is known to be the EGF more accessible to circulation. Therefore, in this study the $[\mathrm{EGF}]_{1 \mathrm{~h}}$ is interpreted as a good estimate of the actual concentration of free EGF in blood circulation (Supplementary Figure S1). Conversely, the EGF measured at $4 \mathrm{~h}[\mathrm{EGF}]_{4 \mathrm{~h}}$ is very close to the concentration plateau achieved by the progressive EGF release by platelets during aggregation (Supplementary Figure S1). Consequently, the $[\mathrm{EGF}]_{4 \mathrm{~h}}$ is interpreted as the average total stock of EGF in the blood sample of an individual.

\section{Measurement of primary variables}

[EGF]: The [EGF] were assessed with the UMELISA EGF ${ }^{\circ}$ kit [20], whose standard is calibrated against the WHO IS EGF 91/530 (NIBSC). Additionally, in a previous study we verified a very good correlation between the UMELISA kit and the widely used Human EGF Immunoassay Quantikine ELISA (R\&D Systems, Minneapolis, MN, USA) (Supplementary Figure S2).

\section{Platelets count}

Blood collected into EDTA-containing test-tubes vacutainer (Becton Dickinson, UK) was assayed in hematological analyzer Mindray BC-3200 (impedance method). We used the reference interval $150-400 \times 10^{9}$ platelets/L, employed at $\mathrm{HAH}$ and commonly accepted in clinical laboratories [21], with thrombocytosis defined as a counting above $400 \times 10^{9}$ platelets/L. Note that, although data reported seem to indicate an associated to aging decrease in platelets count and also statistically significant differences between counting in women and men [22-24], these differences have no practical importance [25] and do not account for separate norms for women and men [26]. Moreover, these differences usually oscillate in the range of variability of platelet's count estimation ( $\leq 6 \%$ for Mindray BC-3200, according to Peng et al. [27]).

\section{Combined variables}

The calculated ratio $\mathrm{r}=[\mathrm{EGF}]_{1 \mathrm{~h}} /[\mathrm{EGF}]_{4 \mathrm{~h}}$ is interpreted as the EGF fraction from the total stock which is available in circulation. Then, the difference $\mathrm{d}=[\mathrm{EGF}]_{4 \mathrm{~h}}$ - $[\mathrm{EGF}]_{1 \mathrm{~h}}$ is interpreted as a measure proportional to the EGF stored in platelets (not available to circulation).

\section{Normalized variables}

We defined several EGF-related variables normalized by platelets count, expressed in grams of EGF per platelet. The $[\mathrm{EGF}]_{1 \mathrm{~h}} /$ platelets/L is interpreted as the average EGF contributed to circulation per platelet. The $[\mathrm{EGF}]_{4 \mathrm{~h}} /$ platelets/L is interpreted as the average total stock of EGF per platelet. Finally, d/platelets/L is interpreted as the average EGF stored per platelet (not in circulation).

\section{Discriminatory capacity of different variables}

The capacity of variables to discriminate between patients (NSCLC1, n=25) and healthy controls (HC3, n=15) was assessed by the nonparametric method for univariate analysis ROC (Receiver Operating Characteristic) [28,29]. The discrimination accuracy achieved by each studied variable was evaluated by the area under curve (AUC) and the associated $\mathrm{p}$ value. For variables with higher/ lower values in patients than in controls, the AUC represents the 
probability that a randomly evaluated patient will have a lower/higher value than a randomly evaluated control. The $\mathrm{p}$ value tests the null hypothesis that the AUC is truly equal to 0.50 (indicating the test is not better at diagnosing than chance). AUC values $>0.70$ with $\mathrm{p}<0.05$ identify the variables with significant discriminatory capacity. A significant $\mathrm{p}$-value in pairwise comparisons of AUCs means the variable with the highest AUC diagnoses significantly better than the others.

\section{Inference of EGF-dependency in NSCLC}

The EGF-dependency of the tumors in different patients was inferred from their stratification by those variables that were found discriminatory in ROC analysis. An optimal cut-off value $\mathrm{C}^{(>/<)}$ (decision threshold) was determined for each variable, by maximizing simultaneously sensitivity- Se (\%) and specificity-Sp (\%) [30]. It was assumed that patients correctly identified by the ROC test (above $\mathrm{C}^{>} /$ below $\mathrm{C}^{<}$) are those with values more anomalous for the evaluated variable, being therefore correctly discriminated with respect to healthy individuals. Consequently, it was inferred that the variables able to better achieve the discrimination might be those chosen to evaluate the stratification of patients, regarding their potential response to treatment with therapies targeting the EGF/EGFR system.

\section{Statistics}

Unpaired Student's t-test was used to compare means $(\alpha=0.05)$. Confounding factors were controlled by design (matching) and by analysis (stratification). Statistical correlations and some associations were assessed with the Pearson's correlation coefficient- $\mathrm{R}$ and by ANOVA or contingency analysis. The statistical packages Statgraphics Centurion XVI, version 16.1.11 and GraphPad Prism 5 were used.

\section{Results}

\section{Serum EGF levels and patient's clinicopathological characteristics}

Table 1 shows the clinicopathological characteristics of the 25 NSCLC patients included in our study, the majority of which classified into metastatic state $(60 \%$ stage IV) or stage III $(36 \%)$. These high percentages were expected, because NSCLC is mostly diagnosed at advanced stages. The majority of patients $(2 / 3)$ was 60 years or older (mean age 62.52 years), which was expected because LC mainly occurs in older people. The predominant skin color was white (76\%), in correspondence with its higher presentation inside our population (>64\% according to the latest Cuban census about population and housing [31]). The proportion of white skin with other (3:1), the ratio men:women, and the predominant ECOG, were very similar to those found in a previous Cuban study [10].

Reports about variation of [EGF] in different subsets of NSCLC patients are scarce and controversial. Therefore, despite our small sample size, we report in Table 1 the average [EGF] measured at $1 \mathrm{~h}$ and $4 \mathrm{~h}$, in naive patients with different clinicopathological characteristics. Note that, as it is explained in section Materials and Methods, $[\mathrm{EGF}]_{1 \mathrm{~h}}$ most likely estimates the concentration of free EGF in circulation, and $[\mathrm{EGF}]_{4 \mathrm{~h}}$ corresponds to the total stock of EGF. Despite the overall small sample size, with the ratios of sampling obtained and $\alpha=0.05$, statistical powers $>0.99$ were reached in the significant differences found between [EGF] in the groups compared. Interestingly, there were no differences between most patient's strata regarding [EGF]. As Lemos-González et al. [11], we did not find association between [EGF] and the stages III and IV of the disease, patient's gender or age, although a tendency to decrease was appreciated for $[\mathrm{EGF}]_{4 \mathrm{~h}}$ in older patients (61-78 years), as it was previously described for healthy individuals [14,32,33]. However, significant differences were found between T3 and T4 status analyzing $[E G F]_{4 h}(p=0.0103)$, but not when $[E G F]_{1 h}$ were compared $(p=0.2740)$. The evaluation of nodal involvement revealed as well, a tendency of [EGF] to decrease at N3 level, as compared to N0 and N2, but without statistical significance.

\section{Serum EGF levels before/after first-line therapy}

Figure 1A illustrates that in NSCLC patients [EGF] at $1 \mathrm{~h}$ and $4 \mathrm{~h}$ were highly variable, at diagnosis (To), as well as after first-line therapy (T1). EGF concentrations at $4 \mathrm{~h}$ were higher than those at $1 \mathrm{~h}$, on average (Figure 1A) and also in the majority of patients, with a few exceptions that showed $[\mathrm{EGF}]_{4 \mathrm{~h}}<[\mathrm{EGF}]_{1 \mathrm{~h}}$ (Figures $1 \mathrm{~B}$ and $1 \mathrm{C}$ ). Overall, in qualitative terms, EGF concentrations in NSCLC patients were highly variable, just as reported earlier in healthy individuals $[14,34,35]$. Moreover, they usually increased with the time of sera separation, just as described for normal subjects $[13,14]$.

Therapy reduced the average $[\mathrm{EGF}]$ in patients, but significantly only circulating levels $\left([\mathrm{EGF}]_{1 \mathrm{~h}}\right.$, Figure $\left.1 \mathrm{~A}\right)$. That decrease was clearly patient-dependent and not described by a simple relation of proportionality. Therefore, while we found a significant, although nonstrong, correlation between [EGF] at $4 \mathrm{~h}$ and $1 \mathrm{~h}$ at diagnosis To (NSCLC1, $\mathrm{n}=24: \mathrm{R}=0.5120, \mathrm{p}=0.0105)$, in treated patients $\mathrm{T} 1$ this correlation was clearly lost (NSCLC2, $\mathrm{n}=18: \mathrm{R}=0.2506, \mathrm{p}=0.3159$ ).

\section{Serum EGF levels in NSCLC patients and controls}

Figure 2 shows the direct comparison of [EGF] between NSCLC patients and groups of healthy individuals well-balanced by age and gender ( $\mathrm{HC} 1$ and $\mathrm{HC} 2)$. There were no differences between these cohorts (Figure 2A) regarding the average total stock of EGF $\left([\mathrm{EGF}]_{4 h}\right)$, neither before (To) nor after chemoradiotherapy (T1). However, the average concentration of free EGF in serum $\left([\mathrm{EGF}]_{1 \mathrm{~h}}\right)$ was significantly higher in naive- but not in treated-patients (Figure 2B). To further compare healthy controls and NSCLC patients, we used the combined variables $\mathrm{r}=[\mathrm{EGF}]_{1 \mathrm{~h}} /[\mathrm{EGF}]_{4 \mathrm{~h}}$ and $\mathrm{d}=[\mathrm{EGF}]_{4 \mathrm{~h}^{-}}[\mathrm{EGF}]_{1 \mathrm{~h}}$, which offer different, but complementary information (see Materials and Methods). We found very significant differences between controls and patients at diagnosis by the variable $\mathrm{r}$ (Figure 2C), which were stronger than those found by comparing $[\mathrm{EGF}]_{1 \mathrm{~h}}$ (Figure $2 \mathrm{~B}$ ). Additionally, $\mathrm{r}$ also caught some difference after treatment, although it was not statistically significant. The variable $d$ however, captured the difference at To similarly to $[\mathrm{EGF}]_{1 \mathrm{~h}}$ and also at T1 (Figure 2D).

Summarizing, our results show differences between healthy individuals and NSCLC patients regarding the accessibility of EGF to circulation, but not regarding the total stock of EGF. Certainly, we observed a higher fraction of free EGF in the circulation of patients ( $r$ ) and consequently a lower amount of EGF stored in platelets (d). These results suggest that the increase in free/accessible EGF in blood circulation is relevant to the biology of NSCLC, most likely because it reflects a higher accessibility to this tumoral growth factor. 
Citation: Idania GP, Hassiul CLH, Camilo RP, Adriana CP, Kalet LM (2018) Normalized Serum EGF Levels as a Potential Biomarker in NonSmall Cell Lung Cancer: The Role of Platelets. J Mol Biomark Diagn 9: 402. doi:10.4172/2155-9929.1000402

Page 4 of 11

\begin{tabular}{|c|c|c|c|c|c|}
\hline \multicolumn{2}{|l|}{ Parameters } & \multirow{2}{*}{$\begin{array}{l}\text { NSCLC1, To } \\
\text { n (\%) } \\
5(20)\end{array}$} & \multirow{2}{*}{$\begin{array}{l}\text { NSCLC2, To } \\
\text { n (\%) } \\
3(17)\end{array}$} & \multirow{2}{*}{$\begin{array}{l}{ }_{[E G F]_{1 h}{ }^{a, b}} \\
(\mathrm{pg} / \mathrm{mL}) \\
803 \pm 228\end{array}$} & \multirow{2}{*}{$\begin{array}{l}{ }_{[E G F]_{4 h}{ }^{a, b}} \\
(p g / m L)\end{array}$} \\
\hline Gender & W & & & & \\
\hline & M & $20(80)$ & $15(83)$ & $627 \pm 80$ & $1010 \pm 75$ \\
\hline \multirow[t]{2}{*}{ Age (years) } & $46-60$ & $11(44)$ & $9(50)$ & $702 \pm 111$ & $1165 \pm 69$ \\
\hline & $61-78$ & $14(56)$ & $9(50)$ & $631 \pm 110$ & $902 \pm 96$ \\
\hline \multirow[t]{2}{*}{ Skin colour } & White & $19(76)$ & $14(78)$ & $648 \pm 98$ & $1029 \pm 83$ \\
\hline & Other & $6(24)$ & $4(22)$ & $706 \pm 102$ & $957 \pm 109$ \\
\hline \multirow[t]{4}{*}{ Primary tumor status } & $\mathrm{T} 1$ & $3(12)$ & $3(17)$ & $757 \pm 83$ & $987 \pm 99$ \\
\hline & T2 & $5(20)$ & $5(28)$ & $555 \pm 231$ & $980 \pm 200$ \\
\hline & T3 & $4(16)$ & $2(11)$ & $868 \pm 285$ & $1364 \pm 110$ \\
\hline & $\mathrm{T} 4$ & $13(52)$ & $8(44)$ & $618 \pm 89$ & $918 \pm 77$ \\
\hline \multirow[t]{4}{*}{ Nodal status } & NO & $7(28)$ & $5(28)$ & $853 \pm 125$ & $1151 \pm 81$ \\
\hline & N1 & $1(4)$ & $0(0)$ & -- & -- \\
\hline & N2 & $6(24)$ & $6(33)$ & $832 \pm 188$ & $1198 \pm 130$ \\
\hline & N3 & $11(44)$ & $7(39)$ & $493 \pm 114$ & $853 \pm 96$ \\
\hline \multirow[t]{4}{*}{ Distant metastasis } & Mo & $10(40)$ & $7(39)$ & $660 \pm 164$ & $1062 \pm 138$ \\
\hline & M1 & $10(40)$ & $7(39)$ & $644 \pm 112$ & $936 \pm 82$ \\
\hline & M1a & $3(12)$ & $2(11)$ & $721 \pm 86$ & $1132 \pm 73$ \\
\hline & M1b & $2(8)$ & $2(11)$ & $676 \pm 27$ & -- \\
\hline \multirow[t]{4}{*}{ Stage } & 1 & $0(0)$ & $0(0)$ & -- & -- \\
\hline & II & $1(4)$ & $1(6)$ & -- & -- \\
\hline & III & $9(36)$ & $6(33)$ & $589 \pm 165$ & $1014 \pm 144$ \\
\hline & IV & $15(60)$ & $11(61)$ & $664 \pm 75$ & $974 \pm 64$ \\
\hline \multirow[t]{2}{*}{ ECOG } & 1 & $24(96)$ & $18(100)$ & - & -- \\
\hline & 2 & $1(4)$ & $0(0)$ & -- & -- \\
\hline \multirow[t]{2}{*}{ Platelets $\left(\times 10^{9} / \mathrm{L}\right)$} & $\leq 400$ & $16(64)$ & $12(67)$ & $709 \pm 93$ & $967 \pm 70$ \\
\hline & $>400$ & $9(36)$ & $6(33)$ & $579 \pm 140$ & $1100 \pm 149$ \\
\hline \multirow{2}{*}{$\begin{array}{l}\text { Primary tumor } \\
\text { Size }(\mathrm{mm})\end{array}$} & $\leq 35$ & $7 / 22(32)$ & $6(33)$ & $685 \pm 115$ & $1114 \pm 57$ \\
\hline & $>35$ & $15 / 22(68)$ & $12(67)$ & $653 \pm 100$ & $977 \pm 87$ \\
\hline \multirow[t]{2}{*}{$1^{\text {st }}$ line-therapy } & $\mathrm{CT}$ & $25(100)$ & $10(56)$ & -- & -- \\
\hline & $\mathrm{CRT}$ & $8(32)$ & $8(44)$ & -- & -- \\
\hline \multirow[t]{2}{*}{ \# of cycles } & $\leq 3$ & 8/24(33) & $3(17)$ & -- & -- \\
\hline & $4-6$ & $16 / 24(67)$ & $15(83)$ & -- & -- \\
\hline
\end{tabular}

Table 1: Demographic and clinicopathological characteristics of NSCLC patients at diagnosis: Its relation with serum [EGF]. 

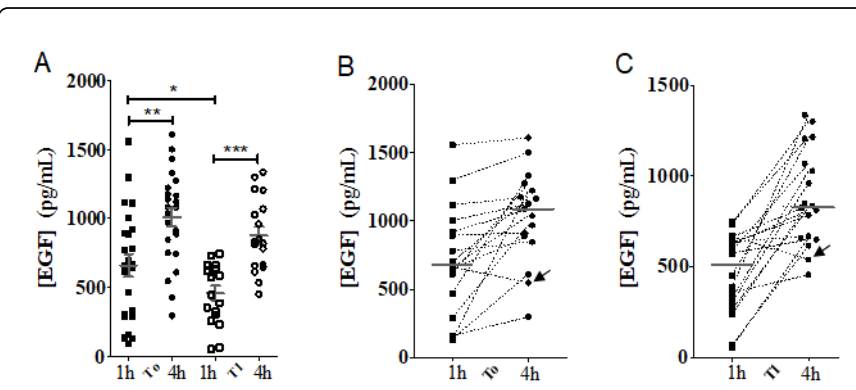

Figure 1: Variability of EGF concentrations in sera of NSCLC patients before/after chemoradiotherapy: Its dependency on the time of sera collection. The picture illustrates: Highly variable [EGF] with higher mean values at $4 \mathrm{~h}$, mean values \pm standard mean errors are represented in gray (A); $[\mathrm{EGF}]_{4 \mathrm{~h}}>[\mathrm{EGF}]_{1 \mathrm{~h}}$ in the majority of patients, excluding some exceptions at To $(3 / 25(12 \%))$ and T1 (1/18 (6\%)), examples are indicated by arrows (B and C).

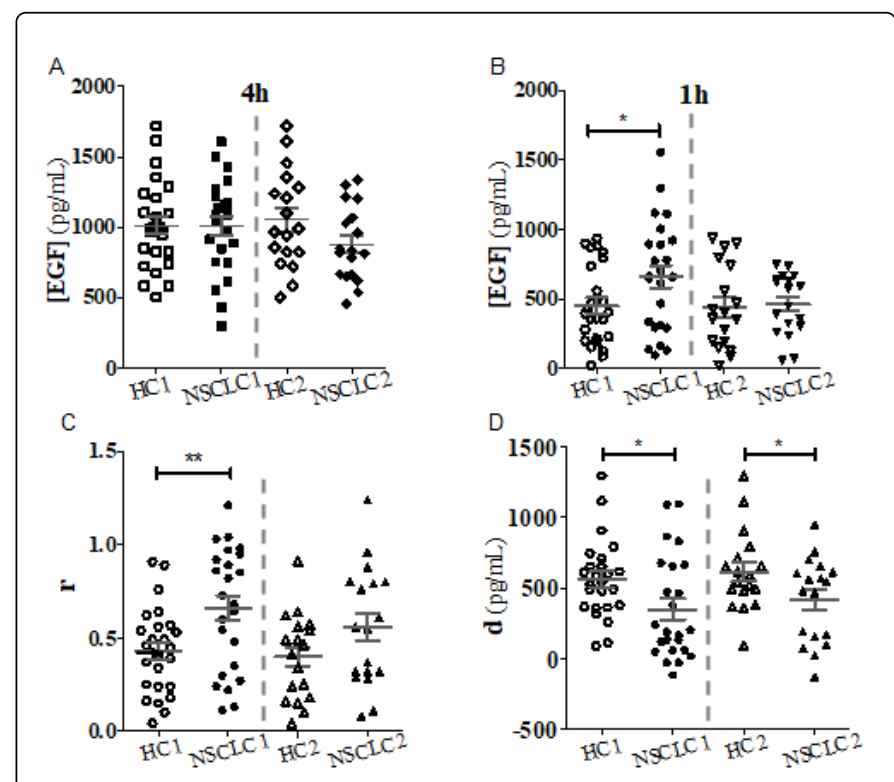

Figure 2: EGF and EGF-combined variables: HC vs. NSCLC patients before/after chemoradiotherapy (NSCLC1/NSCLC2). The picture shows that: patients and controls have on average the same stock of EGF (A); patients have the EGF more accessible to circulation at diagnosis (B); and differences in EGF accessibility are more evident when combined variables are compared (C and $D)$. Mean values \pm standard mean errors are represented in gray.

\section{Serum EGF levels and platelets count in NSCLC patients}

Figure 3A shows extremely significant differences between the count of platelets in controls and patients at diagnosis, with thrombocytosis ${ }^{1}$ present in $36 \%(9 / 25)$ of cases, which is in agreement with other reported incidences [36-38]. Moreover, Figure 3A also shows that chemoradiotherapy reduced platelets count $(\mathrm{p}=0.0072)$ and thrombocytosis $(11 \%(2 / 18))$ although not significantly (Chi-Square $\mathrm{p}=0.0650$, odds ratio $=4.5$ ). Such decreases were expected, as thrombocytopenia is a well-known complication of chemotherapy [39] and can also be induced by radiation [40].

A positive linear correlation between [EGF] and platelets count has been reported in humans [14,41], evidencing that platelets are the main source of EGF in human blood. Therefore, we also studied this correlation in our patients (Figures $3 \mathrm{~B}$ and 3C). Surprisingly, at diagnosis (To) there was no significant correlation between $[E G F]_{1 h}$ or $[E G F]_{4 h}$ and platelets count (Figure 3B). After first-line therapy (T1), however, there was no correlation for $[\mathrm{EGF}]_{1 \mathrm{~h}}$, but a weak correlation was observed for $[\mathrm{EGF}]_{4 \mathrm{~h}}$ (Figure 3C). Altogether, these results show that in NSCLC patients exists a different relationship between EGF and platelets, as compared to that observed in healthy controls. Interestingly, first-line chemoradiotherapy reduces serum EGF concentrations and platelets counts, but also tends to partially recover the correlation between them.

To further study the relation between [EGF] and platelets counts in NSCLC patients, some normalized variables were evaluated (Figures $3 \mathrm{D}-3 \mathrm{~F})$. Figure $3 \mathrm{D}$ shows that the average total stocks of EGF per platelet $\left([\mathrm{EGF}]_{4 \mathrm{~h}} /\right.$ platelets/L) were equal in healthy controls and patients before/after chemoradiotherapy. Conversely, the EGF per platelet accessible to circulation $\left([\mathrm{EGF}]_{1 \mathrm{~h}} /\right.$ platelets/L) was significantly higher in patients, also before/after chemoradiotherapy (Figure 3E), despite the reduction of [EGF] by therapy. Consequently, the EGF stored per platelet $(\mathrm{d} /$ platelets/L) was on average significantly lower in patients at diagnosis $v s$. healthy controls, and slightly lower after therapy ( $p>0.05$, Figure 3F). Therefore, the comparison of cohorts through the normalized variables makes more evident the differences between them, further suggesting an altered relationship between EGF and platelets in NSCLC patients, as contrasted with healthy controls.

Thrombocytosis is a hallmark in NSCLC at diagnosis, therefore, we attempted to understand the relationship between EGF and platelets in this specific context. For this aim, we divided naive patients into two strata, with and without thrombocytosis (platelets counts above $400 \times$ $10^{9}$ platelets/L). We compared in these subgroups the average values of the study variables $[\mathrm{EGF}]_{1 \mathrm{~h}},[\mathrm{EGF}]_{1 \mathrm{~h}} /$ platelets/L and $\mathrm{d} /$ platelets/L (Figures 3G-3I). Interestingly, the average EGF stored per platelet (d/ platelet/L) and the concentration of free EGF $\left([\mathrm{EGF}]_{1 \mathrm{~h}}\right)$ were the same in patients with/without thrombocytosis. However, the EGF in circulation per platelet $\left([\mathrm{EGF}]_{1 \mathrm{~h}} /\right.$ platelets/L) was on average reduced in thrombocytotic patients $(p=0.0239$, Figure $3 \mathrm{H}$ ). Moreover, when the stratification cut-off was established at $350 \times 10^{9}$ platelets/L, the most common used threshold of thrombocytosis [21], this difference was extremely significant ( $\mathrm{p}=0.0005$, data not shown). Overall, these results further suggest the existence of an aberrant relationship between EGF and platelets in NSCLC patients. In thrombocytotic patients there is an increase in total platelets count. These platelets store an amount of EGF similar to that found in patients without thrombocytosis. But, the free

\footnotetext{
${ }^{1}$ Note that HC3 cohort, employed as control in comparisons by platelets count, could not be properly balanced by age and gender (Supplementary Table S2). Nevertheless, the differences are expected not to be significant, given the report of Biino et al. [24], declaring a $9 \times 10^{9} / \mathrm{L}$ decrease in platelets count per each 10 -years of increase in age. This drop is about two orders lower than the difference we found between the compared cohorts. Additionally, gender-related differences in adults are much lower than those related to aging. Moreover, despite the mentioned imbalance, HC3 does not show differences by [EGF], as compared to the properly balanced controls $\mathrm{HC} 1$ and HC2 (Supplementary Table S2).
} 
EGF is slightly lowered in thrombocytotic vs. non-thrombocytotic patients, although is still higher than that in healthy controls.

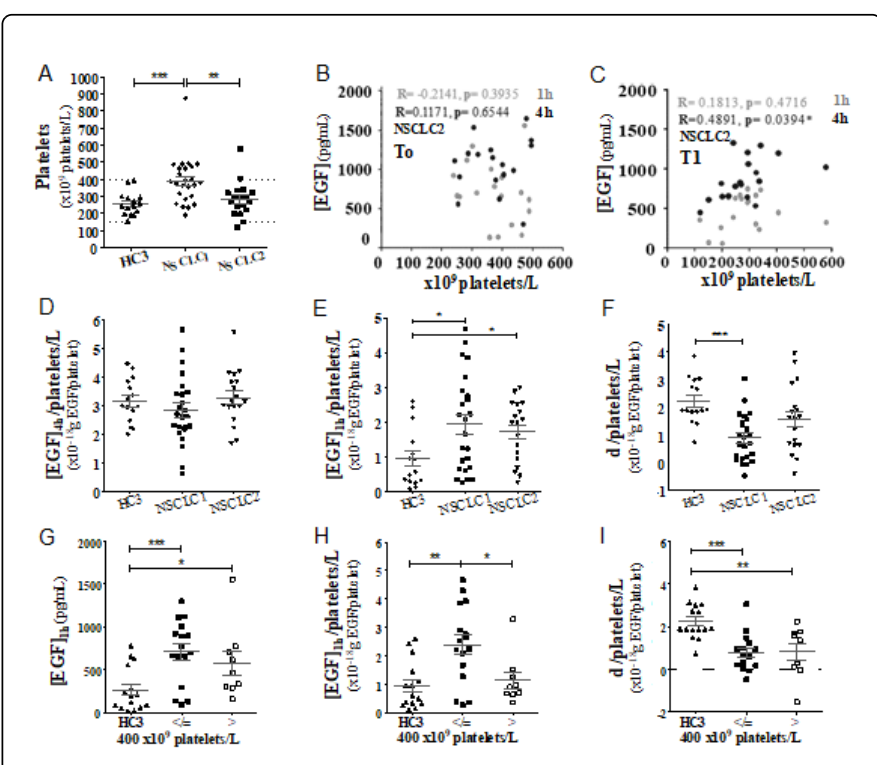

Figure 3: Platelets counts and its relation with EGF levels in NSCLC patients: The effect of chemoradiotherapy. The picture shows that: thrombocytosis is reduced by chemoradiotherapy (A); there is no correlation between [EGF] and platelets count in NSCLC patients at To (B), but first-line therapy restores a weak correlation for $[\mathrm{EGF}]_{4 \mathrm{~h}}$ (C); the normalization of [EGF] by platelets count highlights the higher accessibility of EGF in patients (E and F); the concentration of free EGF $\left([\mathrm{EGF}]_{1 \mathrm{~h}}\right)$ and the average EGF stored per platelet $(\mathrm{d} /$ platelet/L) are the same in patients with and without thrombocytosis ( $\mathrm{G}$ and $\mathrm{I}$ ) but the average EGF contributed to circulation per platelet $\left([\mathrm{EGF}]_{1 \mathrm{~h}} /\right.$ platelets/L) is significantly reduced in thrombocytotic patients $(\mathrm{H})$. Mean values \pm standard mean errors are represented in gray.

\section{Discriminatory capacity of different variables}

Table 2 summarizes the ROC analysis for discrimination between NSCLC patients and healthy controls, for all variables that showed some relevant differences between these cohorts (Figures 2 and 3). With the obtained sample sizes and the ratios healthy/patients in ROC analysis, statistical powers of 0.8-0.9 were achieved in the detection of clinically important differences, at $\alpha=0.05$, according to Obuchowski [42]. Several variables achieved a successful discrimination at diagnosis (To) and after chemoradiotherapy (T1). At To the variables $\mathrm{d}=[\mathrm{EGF}]_{4 \mathrm{~h}}-[\mathrm{EGF}]_{1 \mathrm{~h}}$ and $[\mathrm{EGF}]_{1 \mathrm{~h}} /$ platelets/L discriminated just fairly (AUC 0.70-0.80), $[\mathrm{EGF}]_{1 \mathrm{~h}}, \mathrm{r}$ and platelets/L had good discriminatory capacities (AUC 0.80-0.90), while the variable d/platelets/L reached the best discrimination with an $\mathrm{AUC}=0.8875$. At $\mathrm{T} 1$, however, only the normalized variables had enough accuracy for a fair discrimination.

Figure 4 shows the ROC curves for those variables with higher discriminatory capacities at To and $\mathrm{T} 1$, respectively. The curves cross each other and none of pairwise comparisons were statistically significant. This suggests that all selected variables have a roughly equivalent discriminatory capacity (at least with this relatively small sample size). However, the simultaneous discrimination obtained at To and $\mathrm{T} 1$ with the normalized variables $\left([\mathrm{EGF}]_{1 \mathrm{~h}} /\right.$ platelets $/ \mathrm{L}, \mathrm{d} /$
platelets/L) might favor them as potential candidates for patient's stratification. Actually, d/platelets/L had the highest $\mathrm{pAUC}$ in the range of clinical interest ( $\mathrm{Se} \geq 0.7, \mathrm{Sp} \geq 0.8$ ), among all variables, at To and $\mathrm{T} 1$. This result, along with the absence of bias for this variable under thrombocytosis, might support its choice for stratification purposes before/after first-line therapy.

\section{Inference of EGF-dependency in NSCLC}

EGF levels in circulation, EGFR mutation status and platelets counts have documented implications in prognosis of NSCLC and its response to therapy. The latter fact supports the existence of NSCLC variants with different underlying biology of the EGF/EGFR system. Particularly, the seminal results of Rodriguez et al. [10] suggest the existence of NSCLC patients with different levels of dependency on the availability of EGF in serum. NSCLC patients with high [EGF] have a poor prognosis and respond better to therapy with CIMAvax-EGF vaccine, which induces a deprivation of free EGF in the blood of treated patients. Inspired in these findings, we tried to further infer the dependency on EGF in different NSCLC patients, using the studied above EGF-related variables, for stratification purposes. We reasoned that those variables with a higher capacity for discrimination between patients and healthy controls might better capture the aberrant EGF biology in cancer patients. Therefore, these variables might be better for the identification of those patients probably more sensitive to therapies attempting to normalize EGF/EGFR interactions.

\section{Stratification of patients with study variables}

Patients were stratified using for each study variable the optimal cut-off value $\mathrm{C}^{(>/<)}$, obtained in ROC analysis as explained in Materials and Methods. Patients were predicted as highly EGF-dependent for values of the study variable above $\mathrm{C}^{>}$/below $\mathrm{C}^{<}$, or vice versa, in each specific case. To compare alternative stratifications, its percentages of overlapping in predictions were calculated by pairs of variables (Table 3 ). In this analysis each equal classification of a given patient (either as dependent or as independent of EGF) by two different study variables, directly increases its overlapping percentage.

For the sake of comparison, we also included the stratification method reported by Rodriguez et al. [10], for the identification of patients more benefitted from CIMAvax-EGF vaccine. In Rodriguez's method, patients with [EGF] above the median of the studied population appear to carry tumors apparently more EGF-dependent. To apply this stratification method to our data, the cut-off values $\left(C^{>}\right)$ were set to the medians of either the [EGF] at $1 \mathrm{~h}$ and $4 \mathrm{~h}$. Note that in Rodriguez's report the time of sera separation was not controlled, although it was likely close to our $4 \mathrm{~h}$ processing, since the median [EGF] reported $(873 \mathrm{pg} / \mathrm{ml})$ is close to our value for $[\mathrm{EGF}]_{4 \mathrm{~h}}(829$ $\mathrm{pg} / \mathrm{ml}$ ) in the T1 sample.

Table 3 summarizes the comparison of stratifications achieved with the different variables in our study. At the time of diagnosis (To) the variable $[\mathrm{EGF}]_{1 \mathrm{~h}} /$ platelets/L appears to classify patients quite similarly to variables $\mathrm{d} /$ platelets/L and $[\mathrm{EGF}]_{1 \mathrm{~h}}$, with $83 \%$ and $92 \%$ of coincidence between the overall selections, respectively. Interestingly, the classifications by the medians of $[\mathrm{EGF}]\left([\mathrm{EGF}]_{1 \mathrm{~h}, 4 \mathrm{~h}}\right.$ in Table 3 ) were quite different to those obtained with the normalized variables at To, with the maximal overlapping of about $70 \%$ between $[\mathrm{EGF}]_{1 \mathrm{~h}}{ }^{\mathrm{b}}$ and $[\mathrm{EGF}]_{1 \mathrm{~h}} /$ platelets/L.

Table 3 also shows a low overlapping between the classifications achieved by the EGF-related variables and the variable platelets/L. This 
Citation: Idania GP, Hassiul CLH, Camilo RP, Adriana CP, Kalet LM (2018) Normalized Serum EGF Levels as a Potential Biomarker in NonSmall Cell Lung Cancer: The Role of Platelets. J Mol Biomark Diagn 9: 402. doi:10.4172/2155-9929.1000402

Page 7 of 11

result suggests that both could determine the bad prognosis in patients through different pathways. This is not contradictory, considering that, in addition to EGF, platelets possess an armory of other pro-angiogenic proteins, which can be released under its activation [43]. Moreover, platelets also contain several anti-angiogenic proteins, which are delivered following specific stimuli [44]. Therefore, the classification of patients by platelets might go no via EGF pathway, but through other of these several factors and/or its interactions.

After first-line chemoradiotherapy (T1), the normalized variables showed a remarkably high (94\%) coincidence in patient's classification, and moderate overlappings with $[\mathrm{EGF}]_{1 \mathrm{~h}}{ }^{\mathrm{b}}(82 \%-88 \%)$.
However, the classification by the median of $[\mathrm{EGF}]_{4 \mathrm{~h}} \mathrm{~b}$ showed a very low overlapping with the selections of any other study variable, including $[\mathrm{EGF}]_{1 \mathrm{~h}}^{\mathrm{b}}(53 \%)$.

Overall, our results suggest that normalized variables $[\mathrm{EGF}]_{1 \mathrm{~h}} /$ platelets/L and $\mathrm{d} /$ platelets/L are quite complementary and therefore will classify patients similarly. However, they could provide classifications different to those obtained using the medians of $[E G F]_{1 \mathrm{~h}, 4 \mathrm{~h}} \mathrm{~b}$, as proposed by Rodriguez et al. [10], especially when using $[E G F]_{4 h}$. This result was expected, as we know from our data that $[\mathrm{EGF}]_{4 \mathrm{~h}}$ are unable to discriminate cases from controls.

\begin{tabular}{|c|c|c|c|c|c|c|c|c|c|c|}
\hline \multirow[t]{2}{*}{ Variable } & \multicolumn{5}{|l|}{ To } & \multicolumn{5}{|l|}{ T1 } \\
\hline & AUC & $\mathbf{p}$ & $\mathbf{C}^{\mathrm{a}(>/<)}$ & $\operatorname{Se}(\%)^{b}$ & $\operatorname{Sp}(\%)^{b}$ & AUC & p & $\mathbf{C}^{\mathrm{a}(>/<)}$ & $\mathrm{Se}(\%)^{\mathrm{b}}$ & $\operatorname{Sp}(\%)^{b}$ \\
\hline Platelets/L & 0.8181 & 0.0009553 & $302(>)$ & 75 & 87 & -- & -- & -- & -- & -- \\
\hline$[E G F]_{1 h}$ & 0.8250 & 0.0007371 & $291(>)$ & 83 & 73 & -- & -- & -- & -- & -- \\
\hline$r$ & 0.8278 & 0.0006635 & $0.68(>)$ & 54 & 100 & -- & -- & -- & -- & -- \\
\hline$d$ & 0.7056 & 0.0178 & $239(<)$ & 58 & 100 & -- & -- & -- & -- & -- \\
\hline$[E G F]_{1 h} /$ platelets $/ L$ & 0.7389 & 0.01308 & $0.63(>)$ & 83 & 53 & 0.7431 & 0.0071 & $1.62(>)$ & 65 & 80 \\
\hline $\mathrm{d} /$ platelets/L & 0.8875 & $<0.0001$ & $1.80(<)$ & 92 & 80 & 0.7059 & 0.0349 & $1.84(<)$ & 71 & 80 \\
\hline
\end{tabular}

Table 2: ROC analysis of discriminatory variables.
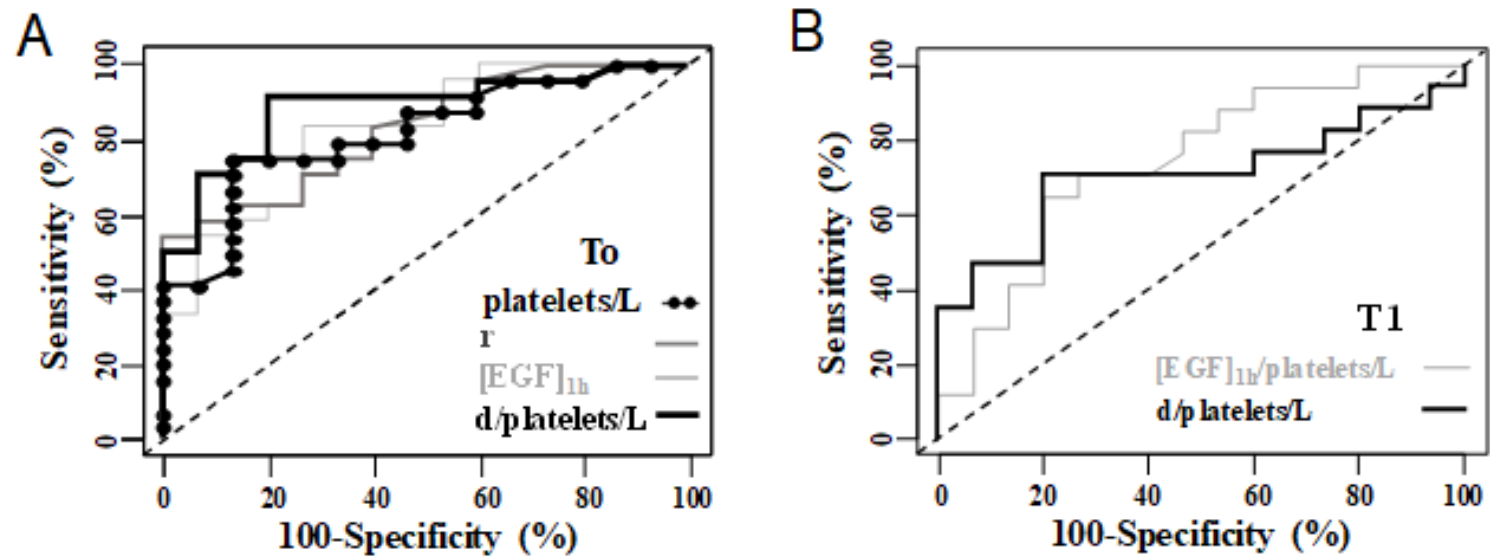

Figure 4: ROC curves for the evaluation of the discriminatory capacity of the study variables. The picture shows the curves of variables with higher AUCs at To (HC3 vs. NSCLC1) (A) and T1 (HC3 vs. NSCLC2) (B).

\section{Discussion}

Overall, EGF concentrations in NSCLC patients were highly variable, just as reported before in healthy people. This natural variability could be mainly attributed to the single nucleotide polymorphism (SNP) at the promoter region of the EGF gene $[45,46]$, which is functional and determines different total stocks of EGF in individuals. Environmental factors could additionally contribute according to Pantsulaia et al. [35].
The higher accessibility of EGF to circulation in NSCLC patients, as compared to healthy controls, suggests that this increase in free/ accessible EGF in blood circulation might be relevant to the biology of NSCLC, most likely because it reflects as well a higher accessibility to this tumoral growth factor by the tumor. Moreover, it is known that platelets are often activated in patients $[47,48]$, which elicits the release of several anti- and pro-angiogenic proteins by them [44], including EGF. Additionally, the circulating tumor cells can induce the degranulation of platelets [49], also provoking the EGF release in 
patients, and its higher accessibility to serum as suggest our results. Previous findings, altogether with the proven efficacy of the EGFtargeted-immunotherapy CIMAvax-EGF, support the involvement of EGF in the biology of cancer.

Our results further suggest the existence of an aberrant relationship between EGF and platelets in NSCLC patients. The correlation [EGF]platelets/L, previously reported for normal individuals [14], is lost in naive patients, probably due to the significant reduction of circulating
EGF levels per platelet under thrombocytosis. Thus, thrombocytosis, an independent indicator of bad prognosis $[36,38,48]$, and low survival and response to therapy in LC [50,51], modifies this correlation. Moreover, the better discrimination achieved by the normalized variables, also confirms the altered relationship EGF-platelets in patients. Finally, the good accuracy of the variable platelets/L in ROC analysis reveals the platelets count as a good surrogate marker of the tumor.

\begin{tabular}{|c|c|c|c|c|c|c|c|c|c|}
\hline \multicolumn{2}{|c|}{ Variable } & \multirow{2}{*}{$\begin{array}{l}\text { Platelets/La } \\
100\end{array}$} & \multirow{2}{*}{$\begin{array}{l}{[E G F]_{1 h^{a}}{ }^{a}} \\
54\end{array}$} & \multirow{2}{*}{$\begin{array}{l}\mathbf{r}^{\mathrm{a}} \\
33\end{array}$} & \multirow{2}{*}{$\begin{array}{l}d^{a} \\
38\end{array}$} & \multirow{2}{*}{$\begin{array}{l}{[E G F]_{1 h} / \text { platelets } / L^{a}} \\
58\end{array}$} & \multirow{2}{*}{\begin{tabular}{|l} 
d/platelets $/ L^{a}$ \\
63
\end{tabular}} & \multirow{2}{*}{$\begin{array}{l}{[E G F]_{1 h^{b}}} \\
42\end{array}$} & \multirow{2}{*}{$\begin{array}{l}{[E G F]_{4 h^{b}}} \\
58\end{array}$} \\
\hline T0 & Platelets/ $\mathrm{L}^{\mathrm{a}}$ & & & & & & & & \\
\hline & {$[E G F]_{1 h^{a}}$} & -- & 100 & 71 & 67 & 92 & 79 & 67 & 63 \\
\hline & $r^{a}$ & -- & -- & 100 & 88 & 71 & 63 & 92 & 50 \\
\hline & $d^{a}$ & -- & -- & -- & 100 & 63 & 67 & 92 & 46 \\
\hline & {$[E G F]_{1 h} /$ platelets/ L $^{a}$} & -- & - & -- & -- & 100 & 83 & 71 & 29 \\
\hline & $\mathrm{d} /$ platelets/ $\mathrm{L}^{\mathrm{a}}$ & -- & -- & -- & -- & -- & 100 & 63 & 21 \\
\hline & {$[E G F]_{1 h^{b}}$} & -- & -- & -- & -- & -- & -- & 100 & 58 \\
\hline & {$[E G F]_{4 h}^{b}$} & -- & -- & -- & -- & -- & -- & & 100 \\
\hline \multirow[t]{4}{*}{$\mathrm{T} 1$} & {$[E G F]_{1 h} /$ platelets/La } & -- & -- & & -- & 100 & 94 & 88 & 41 \\
\hline & $\mathrm{d} /$ platelets/La & -- & & -- & -- & -- & 100 & 82 & 47 \\
\hline & {$[E G F]_{1 h^{b}}$} & -- & -- & -- & -- & -- & -- & 100 & 53 \\
\hline & {$[E G F]_{4 h}{ }^{b}$} & -- & -- & -- & -- & -- & -- & -- & 100 \\
\hline
\end{tabular}

Table 3: Percentages of agreement between different classifications of patients.

Our study has also an added value to the efforts of finding an efficacy biomarker for CIMAvax-EGF ${ }^{\circ}$ vaccine. This vaccine is approved as a second-line therapy, so the selection of patients for this treatment occurs after chemoradiotherapy. Overall, our results suggest that normalized variables $[\mathrm{EGF}]_{1 \mathrm{~h}} /$ platelets/L and $\mathrm{d} /$ platelets/L are quite complementary and therefore will provide similar selections of patients for this treatment. However, they could provide a classification different to that obtained using the median [EGF] as cut-off, especially when using $[E G F]_{4 h}$, a variable which was not able to discriminate cases from controls. Therefore, although in Rodriguez's approach $[\mathrm{EGF}]_{4 \mathrm{~h}}$ could explain in some measure the prognosis of patients and the vaccine's efficacy after chemoradiotherapy [10], we believe that the normalized variables, discriminatory at $\mathrm{T} 1$, might be more valuable for these purposes than $[\mathrm{EGF}]_{4 \mathrm{~h}}$.

\section{Finding's scope}

There are enough proofs supporting the role of EGF/EGFR axis in tumor progression and metastasis in several cancer types. In NSCLC specifically, the EGFR is overexpressed in $40-85 \%$ of cases $[52,53]$. Moreover, this overexpression has been implicated in the process of malignant transformation by promoting cell proliferation, cell survival and motility [54]. The EGF, a potent growth factor measured in numerous tumors [55-62] including LC [12,57], has been implicated in the process of invasion and metastasis [63] and correlated with disease stage, course and prognosis [64]. Additionally, some authors have evidenced the mutual interaction and regulation established between EGF and EGFR. Clark et al. reported that EGF regulates its own receptor [65] and an association between EGFR overexpression and an increased expression of its ligands has also been reported [66]. Consequently, EGF and EGFR are frequently synchronously expressed in gastric [56], lung [52] and other carcinomas. Similarly, minimally invasive colorectal resection is associated with a significant decrease in EGF levels early post operation [57]. All these facts sustain the usefulness of EGF/EGFR as potential biomarkers for several carcinomas.

The status of EGFR was not assessed in our study, which could be considered as a limitation of this work. Several reports have described the role of the expression level and mutational status of EGFR in predicting the efficacy of anti-EGFR therapies [67-71], but the association between the expression of EGFR mutations and response to anti-EGFR treatments in patients is still controversial. This responds to variations in the assessed expressions, caused by the use of different cut-off values for EGFR immunostaining [72], the use of antibodies that do not discriminate between the wild-type and mutated forms of the EGFR [73] and discordances between the expression of EGFR in the primary tumor and the metastatic sites [74,75]. Moreover, the interactions between the EGFR's ligand(s) and the receptor (wild type or mutated), the molecular mechanism of EGFR activation and its 
impact on patient's clinical outcome, are not fully elucidated [73]. The existence of multiple routes for EGFR activation, including a ligandindependent untethering in wild type EGFR (wEGFR), sensitive to differential ligand concentrations, has also been suggested [73,76]. This alternative activation might explain the response to small molecules erlotinib and gefitinib [77], achieved in NSCLC patients with wEGFR (not harboring EGFRvIII). It could also explain the interaction between the overexpressed wEGFR $[78,79]$ and the mAb806 antibody, originally raised against the EGFRvIII mutation [80].

On the other hand, little is known about the mechanisms of action of the anti-EGF antibodies elicited by vaccination with CIMAvax-EGF or its differential activity in tumors with EGFR mutations or other genetic alterations. Nevertheless, this immunotherapy has proven its efficacy in a phase III clinical trial carried out on unselected NSCLC patients with advanced disease [10]. Recently, Rosell et al. [81] published that anti-EGF antibodies generated with this vaccine suppress the EGF-induced cell proliferation, the cycle progression and also inhibit downstream EGFR signaling, in EGFR-mutant NSCLC cell lines sensitive to different generations of EGFR TKIs. Finally, he concludes that patients with an EGFR-mutant can also derive benefit from immunization against EGF, particularly if combined with EGFR TKIs. In summary, Rosell's findings prove the contribution of EGF to NSCLC progression also in patients with a mutant EGFR and hence the possible role of this ligand as a biomarker in this subset of patients too. Therefore, present work's results, along with Rossell's findings, heighten the usefulness of EGF-related variables as biomarkers of efficacy for CIMAvax-EGF treatment, independently of the EGFR mutational status. Further studies including the assessment of mutations and expression of EGFR in NSCLC patients, will validate the applicability of these biomarkers in the context of other EGF/EGFR directed therapies.

\section{Conclusion}

Concluding, our study revealed that what differentiates NSCLC patients from healthy individuals is not the total stock of EGF, but its higher accessibility to serum. Additionally, a different relation between [EGF] and platelets count was observed in patients. Moreover, several EGF-related variables with enough accuracy for discrimination were identified. Particularly, those normalized by platelets count make more evident the differences between patients and controls, and might be potential biomarkers in NSCLC, and good candidate biomarkers of efficacy for CIMAvax-EGF ${ }^{\circ}$ treatment, independently of the patient's EGFR mutational status. Further studies are needed to evaluate the usefulness of these normalized variables on its predictive value to select good responders to treatment with therapies targeting the EGF/ EGFR system, and also in prognosis, monitoring of therapy and evaluation of response, in NSCLC and other epithelial cancers.

\section{Acknowledgements}

The author IGP wants to thank Elizabeth Cuétara Lugo, from the National Institute of Oncology and Radiobiology, in Havana, for the valuable discussions and comments on the manuscript.

\section{References}

1. Lung Cancer Fact Sheet (2016) North America International Association for the Study of Lung Cancer (IASLC).

2. Siegel RL, Miller KD, Jemal A (2015) Cancer statistics. CA Cancer J Clin 65: 5-29.
3. Health Statistics Yearbook 2015 (2016) The Ministry of Public Health. Direction of Medical Records and Health Statistics. Havana.

4. Bianco A, Malapelle U, Rocco D, Perrotta F, Mazzarella G (2018) Targeting immune checkpoints in non-small cell lung cancer. Curr Opin Pharmacol 40: 46-50.

5. Vargas A, Harris C (2016) Biomarker development in the precision medicine era: Lung cancer as a case study. Nat Rev Cancer 16: 525-537.

6. Arteaga C (2003) Targeting HER1/EGFR: A molecular approach to cancer therapy. Semin Oncol 30: 3-14.

7. Crombet T, Camilo P, Neninger E, García B, Lage A (2015) A CIMAvax EGF (EGF-P64K) vaccine for the treatment of non-small-cell lung cancer. Expert Rev Vaccines 14: 1303-1311.

8. Hall R, Gray J, Chiappori A (2013) Beyond the standard of care: A review of novel immunotherapy trials for the treatment of lung cancer. Cancer Control 20: 22-31.

9. McCarthy F, Roshani R, Steele J, Hagemann T (2013) Current clinical immunotherapy targets in advanced Non-Small Cell Lung Cancer (NSCLC). J Leukocyte Biol 94: 1201-1206.

10. Rodriguez P, Popa X, Martínez O, Mendoza S, Santiesteban E, et al. (2016) A phase III clinical trial of the epidermal growth factor vaccine CIMAvax-EGF as Switch maintenance therapy in advanced non-small cell lung cancer patients. Clin Cancer Res 22: 3782-3790.

11. Lemos-González Y, Rodríguez-Berrocal F, Cordero O, Gómez C, Páez De La Cadena M (2007) Alteration of the serum levels of the epidermal growth factor receptor and its ligands in patients with non-small cell lung cancer and head and neck carcinoma. Br J Cancer 96: 1569-1578.

12. Blanco-Prieto S, Vázquez-Iglesias L, Rodríguez-Girondo M, BarciaCastro L, Fernández- Villar A, et al. (2015) Serum calprotectin, CD26 and EGF to establish a panel for the diagnosis of lung cancer. PLoS ONE 10: e0127318.

13. Pesonen K, Viinikka L, Myllyla G, Kiuru J, Perheentupa J (1989) Characterization of material with epidermal growth factor immunoreactivity in human serum and platelets. J Clin Endocrinol Metab 68: 486-491.

14. Gonzalez-Perez I, Cáceres H, Carr A, León K (2017) Measurement of serum EGF levels, a methodological approach: Learning what means "low-/high- concentration of EGF in serum." Some clinical implications. J Mol Biomark Diagn 8: 3.

15. Ramström S (2005) Clotting time analysis of citrated blood samples is strongly affected by the tube used for blood sampling. Blood Coagul Fibrin 16: 447-452.

16. Banks R, Stanley A, Cairns D, Barrett J, Clarke P, et al. (2005) Influences of blood sample processing on low-molecular-weight proteome identified by surface-enhanced laser desorption/ionization mass spectrometry. Clin Chem 51: 1637-1649.

17. Yucel A, Karakus R, Cemalettin A (2007) Effect of blood collection tube types on the measurement of human epidermal growth factor. J Immunoassay Immunochem 28: 47-60.

18. Eisenhauer E, Therasse P, Bogaerts J, Schwartz L, Sargent D, et al. (2009) New response evaluation criteria in solid tumours: Revised RECIST guideline (version 1.1). Eur J Cancer 45: 228-247.

19. Mirsadraee S, Oswal D, Alizadeh Y, Caulo A, Van Beek E (2012) The $7^{\text {th }}$ lung cancer TNM classification and staging system: Review of the changes and implications. World J Radiol 4: 128-134.

20. Castells E, Del Valle R, González E, Melchor A, Pérez P, et al. (2016) An enzyme immunoassay for determining epidermal growth factor (EGF) in human serum samples using an ultramicroanalytical system. J Immunoassay Immunochem 38: 190-201.

21. Butkiewicz A, Kemona H, Dymicka-Piekarska V, Matowicka-Karna J, Radziwon P, et al. (2006) Platelet count, mean platelet volume and thrombocytopoietic indices in healthy women and men. Thrombosis Research 118: 199-204.

22. Buckley M, James J, Brown D, Whyte G, Dean M, et al. (2000) A novel approach to the assessment of variations in the human platelet count. Thromb Haemost 83: 480-484. 
23. Biino G, Gasparini P, D’Adamo P, Ciullo M, Nutile T, et al. (2012) Influence of age, sex and ethnicity on platelet count in five Italian geographic isolates: Mild thrombocytopenia may be physiological. Br J Haematol 157: 384-387.

24. Biino G, Santimone I, Minelli C, Sorice R, Frongia B, et al. (2013) Ageand sex-related variations in platelet count in italy: A proposal of reference ranges based on 40987 subjects' data. PLoS ONE 8: e54289.

25. Bain B (1985) Platelet count and platelet size in males and females. Scand J Haematol 35: 77-79.

26. Brumit D, Barker H (2000) The determination of a reference range for new platelet parameters produced by the Bayer ADVIA TM 120 full blood count analyzer. Clin Lab Haematol 22: 103-107.

27. Peng L, Bai L, Nie L, Wu Z, Yan C (2008) Performance evaluation of BC-3200 hematology analyzer in a university hospital. Int Jnl Lab Hem 30: 205-213.

28. DeLong E, DeLong D, Clarke-Pearson D (1988) Comparing the areas under two or more correlated receiver operating characteristic curves: A nonparametric approach. Biometrics 44: 837-845.

29. Goksuluk D, Korkmaz S, Zararsiz G, Karaağaoğlu A (2016) EasyROC: An interactive web-tool for ROC curve analysis using $\mathrm{R}$ language environment. The R Journal 8: 213-230.

30. Youden W (1950) Index for rating diagnostic tests. Cancer 3: 32-35.

31. Census of Population and Housing (2012) The Color of the skin according to the Census of Population and Housing. Center for Population and Development Studies, National Bureau of Statistics and Information, Republic of Cuba, Edition February, 2016.

32. Uchihashi M, Hirata Y, Fujita T, Matsukura S (1982) Age-related decrease of urinary excretion of human epidermal growth factor (hEGF). Life Sci 31: 679-683.

33. Shurin G, Zoya R, Gurkamal S, Irina L, Michael R, et al. (2007) Dynamic alteration of soluble serum biomarkers in healthy aging. Cytokine 39: 123-129.

34. Baron A, Lafky J, Boardman C, Balasubramaniam S, Suman V, et al (1999) Serum sErbB1 and epidermal growth factor levels as tumour biomarkers in women with stage III o IV epithelial ovarian cancer. Cancer Epidemiol Biomark Prev 8: 129-137.

35. Pantsulaia I, Trofimov S, Kobyliansky E, Livshits G (2004) Heritability of circulating growth factors involved in the angiogenesis in healthy human population. Cytokine 27: 152-158.

36. Pedersen L, Milman N (1996) Prognostic significance of thrombocytosis in patients with primary lung cancer. Eur Respir J 9: 1826-1830.

37. Costantini V, Zacharski L, Moritz T, Edwards R (1990) The platelets count in carcinoma of the lung and colon. Thromb Haemost 64: 501-505.

38. Aoe K, Hiraki A, Ueoka H, Kiura K, Tabata M, et al. (2004) Thrombocytosis as a useful prognostic indicator in patients with lung cancer. Respiration 71: 170-173.

39. Kantarjian H, Giles F, Fenaux P, Boruchov A, Bowen D, et al. (2007) Evaluating safety and efficacy of AMG 531 for the treatment of thrombocytopenic patients with myelodysplastic syndrome (MDS): Preliminary results of a Phase 1-2 study. Proceedings from the annual meeting of the American Society of Clinical Oncology. J Clin Oncol 25: 7032-7032.

40. Lambert MP1, Xiao L, Nguyen Y, Kowalska MA, Poncz M (2011) The role of platelet factor 4 in radiation-induced thrombocytopenia. Int J Radiat Oncol Biol Phys 80: 1533-1540.

41. Lev-Ran A, Hwang D, Snyder D (1990) Human serum and plasma have different sources of epidermal growth factor. Am J Physiol 259: R545R548.

42. Obuchowski N (2005) Fundamentals of clinical research for radiologists. Am J Roentgenol 184: 364-372.

43. Etulain J, Negrotto S, Schattner M (2014) Role of platelets in angiogenesis in health and disease. Curr Angiogenes 3: 48-57.

44. Walsh T, Metharom P, Berndt M (2015) The functional role of platelets in the regulation of angiogenesis. Platelets 26: 199-211.
45. De Mello R (2012) EGF+61 A>G Polymorphisms and lung cancer risk: Future directions. Pulmonar Respirat Med S5: e001.

46. Li T, Ren K, Liu P (2012) Meta-analysis of epidermal growth factor polymorphisms and cancer risk: Involving 9,779 cases and 15,932 controls. DNA Cell Biol 31: 568-574.

47. Jurasz P, North S, Venner P, Radomski M (2003) Matrix metalloproteinase-2 contributes to increased platelet reactivity in patients with metastatic prostate cancer: A preliminary study. Thromb Res 112: 59-64.

48. Gonzalez F, Garcia J, Moldes M, Alvarez J, Rey M, et al. (2010) Platelet count: Association with prognosis in lung cancer. Med Oncol 27: 357-362.

49. Stegner D, Dütting S, Nieswandt B (2014) Mechanistic explanation for platelet contribution to cancer metastasis. Thrombosis Research 133 S2: S149-S157.

50. Jurasz P, Alonso-Escolano D, Radomski M (2004) Platelet-cancer interactions: Mechanisms and pharmacology of tumour cell-induced platelet aggregation. Br J Pharmacol 143: 819-826.

51. Erpenbeck L, Schon M (2010) Deadly allies: The fatal interplay between platelets and metastasizing cancer cells. Blood 115: 3427-3436.

52. Bunn J, Franklin W (2002) Epidermal growth factor receptor expression, signal pathway and inhibitors in non-small cell lung cancer. Semin Oncol 29: 38-44.

53. Ettinger D (2006) Clinical implications of EGFR expression in the development and progression of solid tumors: Focus on non-small cell lung cancer. The Oncologist 11: 358-373.

54. Mendelsohn J, Baselga J (2003) Status of epidermal growth factor receptor antagonists in the biology and treatment of cancer. J Clin Oncol 21: 2787-2799.

55. Aigner A, Brachmann P, Beyer J, Jäger R, Raulais D, et al. (2003) Marked increase of the growth factors pleiotrophin and fibroblast growth factor-2 in serum of testicular cancer patients. Annals of Oncol 14: 1525-1529.

56. Yam W, Hata J, Yokozakhi H, Nakatanai I, Ochiaih T, et al. (1988) Interaction between epidermal growth factor and its receptor in progression of human gastric carcinoma. Int J Cancer 41: 211-217.

57. Erol-Demirbilek M, Komurcu H, Komurcu S, Kilic N (2013) EGF and TNF-a levels and oxidative/nitrosative stress in breast and non-small cell lung cancer patients. Hacettepe J Biol \& Chem 41: 357-363.

58. Grieco M, Kumara S, Baxter R, Dujovny N, Kalady M, et al. (2010) Minimally invasive colorectal resection is associated with a rapid and sustained decrease in plasma levels of epidermal growth factor (EGF) in the colon cancer setting. Surg Endosc 24: 2617-2622.

59. Soulitzis N, Karyotis I, Delakas D, Spandidos D (2006) Expression analysis of peptide growth factors VEGF, FGF2, TGFB1, EGF and IGF1 in prostate cancer and benign prostatic hyperplasia. Int J Oncol 29: 305-314.

60. Friess H, Berberat P, Schilling M, Kunz J, Korc M, et al. (1996) Pancreatic cancer: The potential clinical relevance of alterations in growth factors and their receptors. J Mol Med (Berl) 74: 35-42.

61. Gansauge F, Gansauge S, Schmidt E, Müller J, Beger H (1998) Prognostic significance of molecular alterations in human pancreatic carcinoma an immunohistological study. Langenbecks Arch Surg 383: 152-155.

62. Kemik O, Sarbay A, Purisa S, Adas M, Hasırcı I, et al. (2010) Serum levels of VEGF and EGF in thyroid gland tumors. Tip Araştırmaları Dergisi 8: 112-115.

63. Fayette J, Le Chevalier T, Soria J (2003) Therapeutic implications of epidermal growth factor receptor in lung cancer. Bull Cancer 90: S233-240

64. Kuroi K, Toi M (2001) Circulating angiogenesis regulators in cancer patients. Int J Biol Markers 16: 5-26.

65. Clark A, Ishii S, Richert N, Merlino G, Pastan I (1985) Epidermal growth factor regulates the expression of its own receptor. PNAS 82: 8374-8378.

66. Rubin J, Melhem M, Gooding W, Day R, Holst V, et al. (1998) Levels of TGF-a and EGFR protein in head and neck squamous cell carcinoma and patient survival. J Natl Cancer Inst 90: 824-832. 
Citation: Idania GP, Hassiul CLH, Camilo RP, Adriana CP, Kalet LM (2018) Normalized Serum EGF Levels as a Potential Biomarker in NonSmall Cell Lung Cancer: The Role of Platelets. J Mol Biomark Diagn 9: 402. doi:10.4172/2155-9929.1000402

Page 11 of 11

67. Stintzing S, Jung A, Kapaun C, Reiche J, Paul D, et al. (2012) Ligand expression of the EGFR ligands amphiregulin, epiregulin, and amplification of the EGFR gene to predict for treatment efficacy in KRAS wild-type mCRC patients treated with cetuximab plus CAPIRI and CAPOX: Analysis of the randomized AIO CRC-0104 trial. J Clin Oncol 30: 3519 .

68. Mok T, Wu Y, Thongprasert S, Yang C, Chu D, et al. (2009) Gefitinib or carboplatin-paclitaxel in pulmonary adenocarcinoma. N Engl J Med 361: 947-957.

69. Maemondo M, Inoue A, Kobayashi K, Sugawara S, Oizumi S, et al. (2010) Gefitinib or chemotherapy for non-small-cell lung cancer with mutated EGFR. N Engl J Med 362: 2380-2388.

70. Pao W, Miller V, Zakowski M, Doherty J, Politi K, et al. (2004) EGF receptor gene mutations are common in lung cancers from "never smokers" and are associated with sensitivity of tumors to gefitinib and erlotinib. PNAS 101: 13306-13311.

71. Jamal-Hanjani M, Spicer J (2011) Epidermal growth factor receptor tyrosine kinase inhibitors in the treatment of epidermal growth factor receptor-mutant non-small cell lung cancer metastatic to the brain. Clin Cancer Res 18: 938-944.

72. Khelwatty S, Essapen S, Bagwan I, Green M, Seddon A, et al. (2014) Coexpression of HER family members in patients with Dukes' C and D colon cancer and their impacts on patient prognosis and survival. PLoS One 9: e91139.

73. Orellana L, Hospital A, Orozco M (2014) Oncogenic mutations of the EGF-Receptor ectodomain reveal an unexpected mechanism for ligandindependent Activation. BioRxiv, Cold Spring Harbor Laboratory.

74. Yarom N, Marginean C, Moyana T, Gorn-Hondermann I, Birnboim H, et al. (2010) EGFR expression variance in paired colorectal cancer primary and metastatic tumors. Cancer Biol Ther 10: 416-421.
75. Khelwatty S, Essapen S, Bagwan I, Green M, Seddon A, et al. (2017) The impact of co-expression of wild-type EGFR and its ligands determined by immunohistochemistry for response to treatment with cetuximab in patients with metastatic colorectal cancer. Oncotarget 8: 7666-7677.

76. Guo G, Gong K, Wohlfeld B, Hatanpaa K, Zhao D, et al. (2017) LigandIndependent EGFR Signaling. Cancer Res 75: 1-6.

77. Jackman D, Yeap B, Sequist L, Lindeman N, Holmes A, et al. (2006) Exon 19 deletion mutations of epidermal growth factor receptor are associated with prolonged survival in non-small cell lung cancer patients treated with gefitinib or erlotinib. Clin Cancer Res 12: 3908-3914.

78. Jungbluth A, Stockert E, Huang H, Collins V, Coplan K, et al. (2003) A monoclonal antibody recognizing human cancers with amplification/ overexpression of the human epidermal growth factor receptor. Proc Natl Acad Sci 100: 639-644.

79. Gan H, Walker F, Burgess A, Rigopoulos A, Scott A, et al. (2007) The epidermal growth factor receptor EGFR) tyrosine kinase inhibitor AG1478 increases the formation of inactive untethered EGFR dimers. Implications for combination therapy with monoclonal antibody $806 . \mathrm{J}$ Biol Chem 282: 2840-2850.

80. Mishima K, Johns T, Luwor R, Scott A, Stockert E, et al. (2001) Growth suppression of intracranial xenografted glioblastomas overexpressing mutant epidermal growth factor receptors by systemic administration of monoclonal antibody (mAb) 806, a novel monoclonal antibody directed to the receptor. Cancer Res 61: 5349-5354.

81. Codony-Servat J, García-Roman S, Molina-Vila M, Bertran-Alamillo J, Giménez-Capitán A, et al. (2018) Anti-epidermal growth factor vaccine antibodies enhance the efficacy of tyrosine kinase inhibitors and delay the emergence of resistance in EGFR mutant lung cancer cells. J Thorac Oncol 13: 1324-1337. 